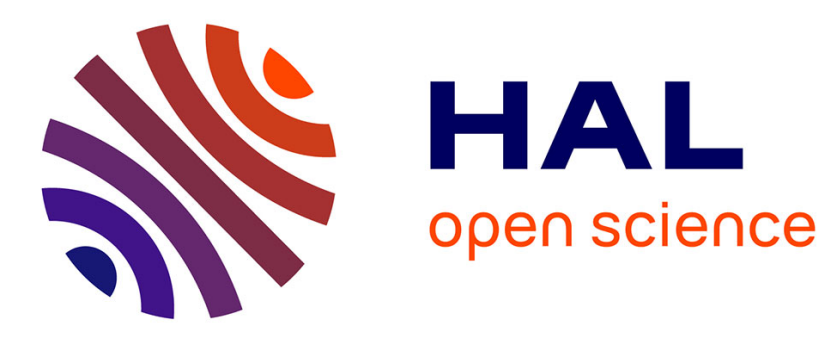

\title{
Role of GPR30 in the mechanisms of tamoxifen resistance in breast cancer MCF-7 cells
}

Atanas Ignatov, Tanja Ignatov, Albert Roessner, Serban Dan Costa, Thomas Kalinski

\section{- To cite this version:}

Atanas Ignatov, Tanja Ignatov, Albert Roessner, Serban Dan Costa, Thomas Kalinski. Role of GPR30 in the mechanisms of tamoxifen resistance in breast cancer MCF-7 cells. Breast Cancer Research and Treatment, 2009, 123 (1), pp.87-96. 10.1007/s10549-009-0624-6 . hal-00535413

\section{HAL Id: hal-00535413 https://hal.science/hal-00535413}

Submitted on 11 Nov 2010

HAL is a multi-disciplinary open access archive for the deposit and dissemination of scientific research documents, whether they are published or not. The documents may come from teaching and research institutions in France or abroad, or from public or private research centers.
L'archive ouverte pluridisciplinaire HAL, est destinée au dépôt et à la diffusion de documents scientifiques de niveau recherche, publiés ou non, émanant des établissements d'enseignement et de recherche français ou étrangers, des laboratoires publics ou privés. 


\title{
Role of GPR30 in the mechanisms of tamoxifen resistance in breast cancer MCF-7 cells
}

\author{
Atanas Ignatov • Tanja Ignatov • Albert Roessner • \\ Serban Dan Costa • Thomas Kalinski
}

Received: 2 October 2009/Accepted: 28 October 2009/Published online: 13 November 2009

(C) Springer Science+Business Media, LLC. 2009

\begin{abstract}
Tamoxifen is the most frequently used antihormonal drug for treatment of women with hormonedependent breast cancer. The aim of this study is to investigate the mechanism of tamoxifen resistance and the impact of the new estrogen G-protein coupled receptor (GPR30). MCF-7 cells were continuously exposed to tamoxifen for 6 months to induce resistance to the inhibitory effect of tamoxifen. These tamoxifen-resistant cells (TAM-R) exhibited enhanced sensitivity to 17-ß-estradiol and GPR30 agonist, G1, when compared to the parental cells. In TAM-R cells, tamoxifen was able to stimulate the cell growth and MAPK phosphorylation. These effects were abolished by EGFR inhibitor AG1478, GPR30 antisense oligonucleotide, and the selective c-Src inhibitor PP2. Only EGFR basal expression was slightly elevated in the TAM-R cells, whereas GPR30 expression and the basal phosphorylation of Akt and MAPK remained unchanged when compared to the parental cells. Interestingly, estrogen treatment significantly increased GPR30 translocation to the cell surface, which was stronger in TAM-R cells. Continuous treatment of MCF-7 cells with GPR30 agonist G1 mimics the long-term treatment with tamoxifen and increases drastically its agonistic activity. This data
\end{abstract}

Atanas Ignatov and Tanja Ignatov contributed equally to this work.

A. Ignatov $(\bowtie) \cdot$ T. Ignatov $\cdot$ S. D. Costa $(\bowtie)$

Department of Obstetrics and Gynecology, Otto-von-Guericke

University, G.-Hauptmann Str. 35, 39108 Magdeburg, Germany

e-mail: atanas.ignatov@med.ovgu.de

S. D. Costa

e-mail: serban-dan.costa@med.ovgu.de

A. Roessner - T. Kalinski

Department of Pathology, Otto-von-Guericke University,

Magdeburg, Germany suggests the important role of GPR30/EGFR receptor signaling in the development of tamoxifen resistance. The inhibition of this pathway is a valid option to improve antihormone response in breast cancer.

Keywords GPR30 - Breast cancer ·

Tamoxifen resistance $\cdot$ Estrogen

\section{Introduction}

Tamoxifen (Tam) is the most frequently used anti-hormonal drug for treatment of women with hormone-dependent breast cancer. Tam treatment is very effective in tumors expressing estrogen receptors (ER) and significantly reduces the mortality of breast cancer patients $[1,2]$. However, during the treatment almost all tumors developed resistance to Tam and several cellular mechanisms have been discussed to be responsible for this development [3]. The reduction or loss of ER expression, quantitative or qualitative change in ER-related co-factors, impaired metabolism of hormonal agents [Cytochrom P450 2D6 (CYP2D6) variants] could contribute to the development of endocrine-resistant breast cancers [3]. Nevertheless, several experimental studies have revealed that increased growth factor signaling can play an important role in the development of Tam resistance. Growth factors and their intracellular signaling pathways can stimulate ER activity in the absence of a ligand termed "ligand-independent" activation of ERs. It has been proposed that this phenomenon is associated with the overexpression of EGFR and human epidermal growth factor receptor-2 (Her-2) [4, 5] and is particularly mediated via estrogen activation of MAPK signaling pathway [6]. Moreover, this data is supported by a clinical finding revealing that Tam resistance is 
related to overexpression of EGFR and/or Her-2 [3]. These tumors are more aggressive and resistant to endocrine therapy.

An orphan G-protein coupled receptor, GPR30, was recently claimed to be a new membrane-bound estrogen receptor involved in the rapid nongenomic effects of estrogen (for review [7]). It belongs to the family of G-protein coupled receptors (GPCRs), which are membrane proteins activated by various ligands, such as hormones, neurotransmitters, chemokines, odorants, and small peptides. Evidence that GPR 30 acts independently of ER $\alpha$ and $\operatorname{ER} \beta$ is provided by the fact that rapid estrogen action does not have to correlate with the expression of $\mathrm{ER} \alpha$ and $\mathrm{ER} \beta$ proteins and can occur in SKBR3 breast cancer cells that lack the mRNA for both the receptors [8]. GPR30 mediates the proliferative effects of estrogen in breast cancer cells, endometrial cancer cells, and in ovarian cancer cells [8]. Particularly in breast cancer cells, GPR30 activates and releases heparin-bound growth factor (HB-EGF), which in turn activates the epidermal growth factor receptor (EGFR) [9]. Thus, the GPR30 and EGFR would be considered vehicles for estrogen action. That suggests that GPR30 signaling may contribute to tumor growth and resistance to endocrine therapy.

\section{Materials and methods}

\section{Materials}

All chemicals and antibiotics for a cell culture were obtained from Sigma-Aldrich (Steinheim, Germany). 4-OH-tamoxifen (Tam), 17-ß-estradiol (E2), fulvestrant, Tyrphostin AG1478, and c-Src inhibitor PP2 were purchased from Sigma-Aldrich. GPR30 agonist G1 was obtained from Calbiochem (Darmstadt, Germany). GPR30 antibody, Calnexin antibody, and 5'-nucleotidase antibody were from antibodies-online (Aachen, Germany). The antibodies against total and phosphorylated MAPK, total and phosphorylated Akt, EGFR and B-actin were from Cell Signaling (Frankfurt am Main, Germany). IMEM Medium was obtained from Biochrom (Berlin, Germany). GPR30 anti-sense oligonucleotides were purchased from Biomers (Ulm, Germany). Lipofectamin 2000 transfection reagent was obtained from Invitrogen (Karlsruhe, Germany).

\section{Cell culture}

Wild-type MCF-7 cells (MCF-7WT) were obtained from ATCC (Manassas, VA) and were routinely grown in cultured IMEM medium containing 5\% fetal calf serum (FCS), $100-\mathrm{U} / \mathrm{ml}$ penicillin, and $100-\mu \mathrm{g} / \mathrm{ml}$ streptomycin. TAM-R cells were derived from MCF-7WT cells by continuous exposure to Tam diluted in $0.1 \%$ ethanol. The control cells were obtained by exposure to medium containing $0.1 \%$ ethanol. TAM-R cells were cultured continuously in medium containing 5\% charcoal-stripped steroid-depleted FCS supplemented with 10-nM Tam. The growth media were replaced every 3 days. G1-R cells were derived from MCF-7WT cell continuously cultured in medium containing 1-nM G1 diluted in 0.1\% DMSO. The matched control cells were cultured in medium containing $0.1 \%$ DMSO. G1-R cells were cultured in phenol-red-free medium containing $5 \%$ charcoal-stripped FCS. The cells were maintained at $37^{\circ} \mathrm{C}$ in a humidified $5 \% \mathrm{CO}_{2}$ atmosphere.

The cells were used as a pool of clones. They were seeded in 6-well plates at a density of 60,000 cells per well. Two days later the cells were treated as described in figure legends. At the end of treatment, cells were rinsed twice with saline and counted using a Coulter counter as described [10]. To test the inhibitory effect of Tam or fulvestrant, the cells were incubated in medium containing 5\% FCS or 10-nM E2. For assaying the stimulatory effect of E2 and G1, the cells were grown in phenol-red-free medium with charcoal-stripped FCS. Then cells were incubated with an appropriate agent for 5 days before counting. To test the effect of different cell signaling inhibitors the cells were preincubated with the inhibitor in concentration and time indicated in figure legends.

Experiments with GPR30 anti-sense oligonucleotides

For these experiments, the cells were washed twice in phosphate-buffered saline, then transfected with $0.2-\mu \mathrm{M}$ GPR30 anti-sense oligonucleotide (5'-TTGGGAAGTCAC ATCCAT- $\left.3^{\prime}\right)$ or with $0.2-\mu \mathrm{M}$ random control $\left(5^{\prime}\right.$-GATC TCAGCACGGCAAAT- $3^{\prime}$ ). The transfection was performed with Lipofectamine 2000 transfection reagent as previously described [11]. The experiments were performed $24 \mathrm{~h}$ after transfection.

\section{Inhibition assay}

For experimentation, the cells were seeded in 6-well plates and incubated in phenol-red-free medium supplemented with 5\% charcoal-stripped steroid-depleted FCS. Two days later the cells were pretreated for $1 \mathrm{~h}$ with $1-\mu \mathrm{M}$ AG1478, 5- $\mu \mathrm{M}$ PP2, or $1-\mu \mathrm{M}$ fulvestrant. After that, they were treated for 5 days with $1-\mu \mathrm{M}$ Tam or 10 nM E2 and the cell count was measured using a Coulter counter as described [11]. Control cells were treated only with medium. The cell number was expressed as percent (\%) of control. 
Western blotting

Protein cell lysis and Western blotting procedures were performed as previously described [11]. The subcellular protein fractions were extracted using cell compartment kit from Qiagen (Hilden, Germany) following the manufacturer's instructions. $25 \mu \mathrm{l}$ of the samples were separated by sodium dodecylsulfate polyacrylamide gel electrophoresis (SDS-PAGE) and blotted onto nitrocellulose membranes. The membranes were blocked with $3 \%$ dry milk in tris buffered saline with Tween 20 (TBS/ Tween) and incubated for $2 \mathrm{~h}$ at room temperature (RT) with antibodies against GPR30, diluted 1:1000, total or phosphorylated MAPK diluted 1:2000, total or phosphorylated Akt, diluted 1:1000, EGFR diluted 1:100, and B-actin diluted 1:10000. A peroxidase-conjugated antirabbit antibody, diluted 1:10000, was used for a second incubation (30 min at RT). West Pico Supersignal substrate (Perbio, Bonn, Germany) was left on the membrane until distinct bands had developed. A MagicMark standard (Invitrogen) was used to identify the molecular weights. The enhanced chemiluminescence membrane images were quantified using the GeneGnome and GeneTools image scanning and analysis package (Syngene, Cambridge, UK).

\section{Statistical analysis}

The results are expressed as means of six determinations \pm SD. Curve fittings were performed with the Prism program (Graph Pad Software, San Diego, CA, USA). Statistical analysis was carried out using Student's $t$ test for paired observations. When three or more means were compared, analysis of variance was applied using the Prism program. Results were considered statistically significant if the $P$ value was $<0.05$.

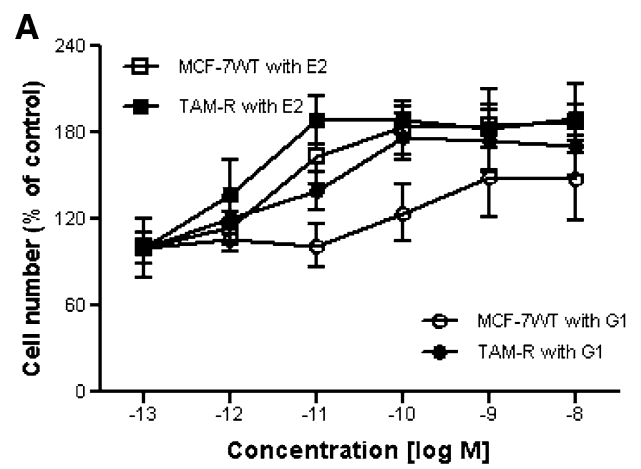

Fig. 1 Effect of 17-ß-estradiol (E2), GPR30 agonist G1, and Tam on proliferation in parental hormone-sensitive breast cancer cells (MCF7WT) and in Tam-resistant (TAM-R) cells. a Cells were treated with indicated concentration of E2 and G1 for 5 days and the cell number

\section{Results}

Enhanced response of MCF-7 cells to G1 and E2 stimulation after long-term Tam exposure

The growth effect of 17-ß-estradiol (E2) and GPR30 agonist G1 was tested. As expected, E2 induced significant growth stimulation of wild-type MCF-7 cells (MCF-7WT) without supplementation with 5\% FCS, whereas GPR30 agonist G1 increased the cell growth slightly (Fig. 1a). Exposure of the MCF-7WT to Tam caused concentrationdependent reduction in cell number (Fig. 1b). To generate a cell line resistant to Tam, MCF-7WT cells were continuously grown in medium containing 10-nM Tam and were termed TAM-R cells. Since Tam was dissolved in $0.1 \%$ ethanol, MCF-7WT cells continuously treated with $0.1 \%$ ethanol were used as controls. Prolonged treatment (over 6 months) of MCF-7WT cells with Tam alters the inhibitory effect of Tam significantly, whereas the exposure to ethanol did not abolish this response (Fig. 1a). Only the higher concentration of Tam remained to be inhibitory for TAM-R cells. The long-term stimulation of the wild-type cells with Tam increased the sensitivity of MCF-7 cells to the stimulatory effect of E2 and G1. As demonstrated in Fig. 1a, the long-term treatment with Tam caused a shift of E2 and G1 dose response curves to the left.

Phosphorylation of MAPK and Akt kinases in response to $\mathrm{E} 2, \mathrm{G} 1$, and Tam

Since activation of MAPK and Akt is an important mechanism involved in resistance to Tam [12, 13], we assayed the effect of E2, Tam, and GPR30 agonist G1 on phosphorylation of MAPK and Akt in TAM-R cells and compared them to control cells. TAM-R cells responded with increase sensitivity to both E2 and G1. After treatment

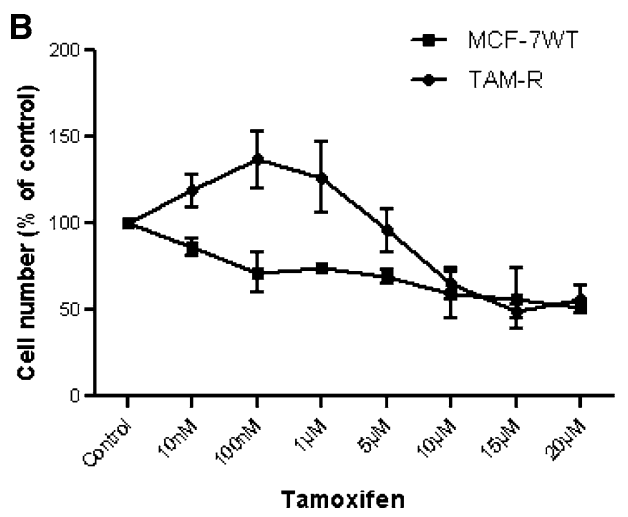

was counted. b MCF-7WT and TAM-R cells were treated with different concentrations of Tam for 5 days and the cell number was counted. Each experiment was repeated at least three times. The results are expressed as means $\pm \mathrm{SD}$ 
with 10-nM E2 or 1-nM G1 for the indicated time, TAM-R cells showed an earlier and significantly increased level of MAPK phosphorylation when compared to the control cells (Fig. 2a, b). Significant increase of E2-induced MAPK phosphorylation in TAM-R cells was observed after 3-min incubation (Fig. 2a). In control cells, the E2-induced MAPK phosphorylation increased significantly slower: after 15-min incubation. The level of phosphorylation was not significantly different. E2 treatment did not influence the level of Akt phosphorylation in both control and TAM$\mathrm{R}$ cells (Fig. 2a).

Treatment with 1-nM G1 led to an increase in phosphorylation level of both MAPK and Akt (Fig. 2b). In TAM-R cells, the level of phosphorylation was significantly higher, started to increase at $3 \mathrm{~min}$ and decreased at $10 \mathrm{~min}$ to the basal level. In control cells, the MAPK phosphorylation also increased at $3 \mathrm{~min}$, but was weaker when compared to the TAM-R cells and decreased markedly at $15 \mathrm{~min}$. The phosphorylation of Akt in TAM-R cells increased at 3-5 min incubation with G1 and decreased to the basal level at $10 \mathrm{~min}$ (Fig. 2b). In control cells, stimulation of Akt occurred initially after 15-min incubation with $\mathrm{G} 1$.

In contrast, Tam significantly inhibited the MAPK phosphorylation in the control cells and was detectable after 10-min Tam treatment (Fig. 2c). However, in TAM-R cells, Tam was able to activate MAPK phosphorylation with peak stimulation at 5 and $10 \mathrm{~min}$. The phosphorylation level of Akt remained constant. These results demonstrated that Tam agonistic activity was increased in TAM-R cells.

GPR30/growth factor receptor signaling in TAM-R cells

Very recently, it has been reported that GPR30 can stimulate the phosphorylation of MAPK and Akt via activation of EGFR [9]. This fact and the observation that TAM-R

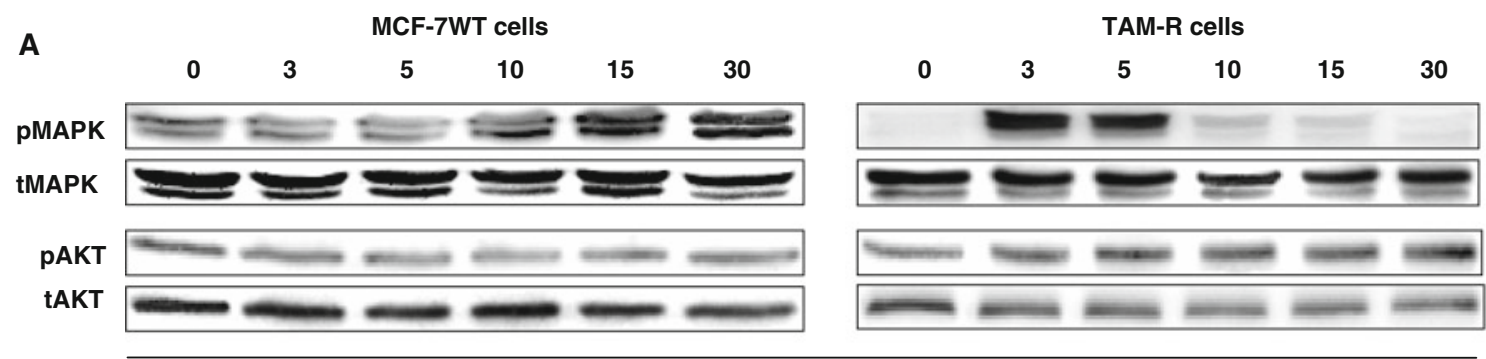

E2 10nM

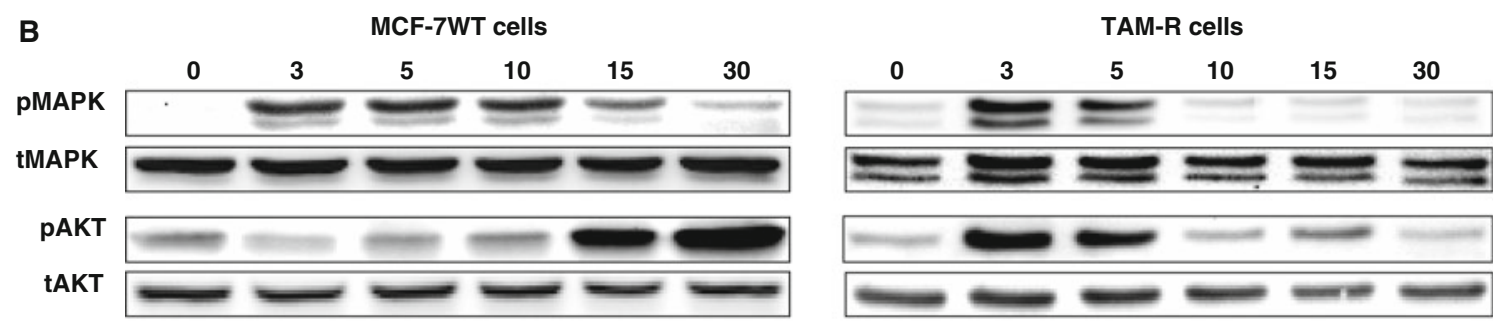

G1 1nM

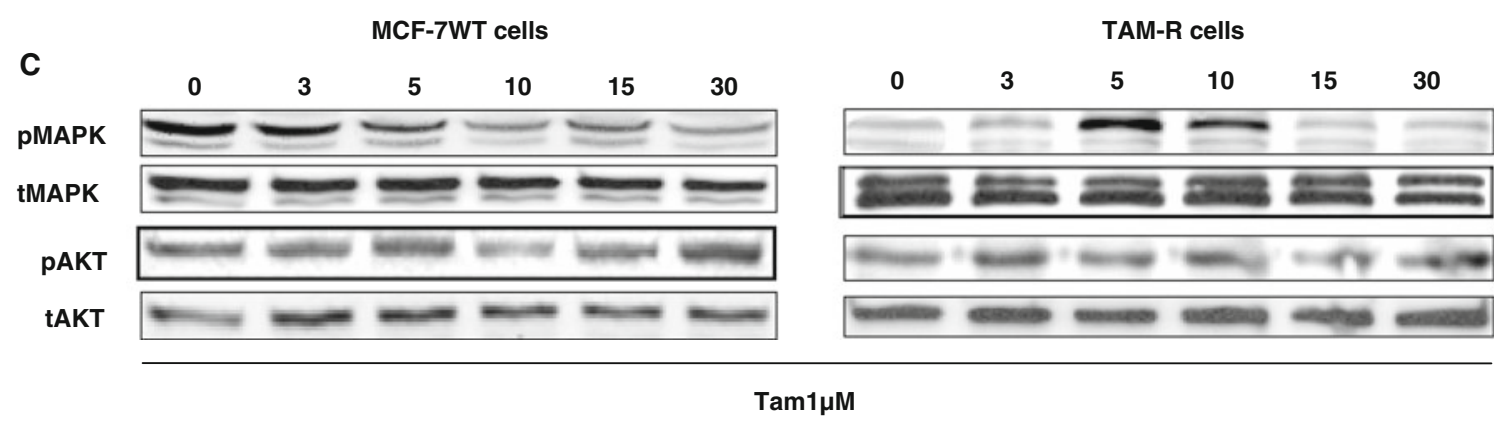

Fig. 2 Phosphorylation of MAPK and Akt in MCF-7WT and TAM-R cells. The expression of MAPK and Akt was investigated by Western blot analysis using specific antibodies against phosphorylated (p) and total (t) proteins. Cells were cultured for the indicated time with 10nM E2 (a), 10-nM G1 (b), and 1- $\mu \mathrm{M}$ Tam (c) and after preparation of the cell lysates the Western blot was performed 
cells were more sensitive to GPR30 agonist G1 made us to investigate the cross talk between GPR30 and growth factor receptor signaling pathway in acquired Tam resistance. Using Western blotting, the basal levels of GPR30, EGFR, MAPK, and Akt expressions in TAM-R cells were investigated and compared to their basal levels in control cells. As shown in Fig. 3a, there was no significant difference in the levels of protein expression of GPR30, as well as in the phosphorylation level of MAPK and Akt, between TAM-R cells, treated for 2, 4, and 6 months with Tam, and the control cells incubated with ethanol. However, EGFR levels were slightly increased in TAM-R cells when compared to the control cells (Fig. 3a). A slight increase in basal level of EGFR was observed after 4 months of Tam treatment, reaching a maximal level at 6 months (Fig. 3a), and remained unchanged during further treatment with Tam (data not shown).
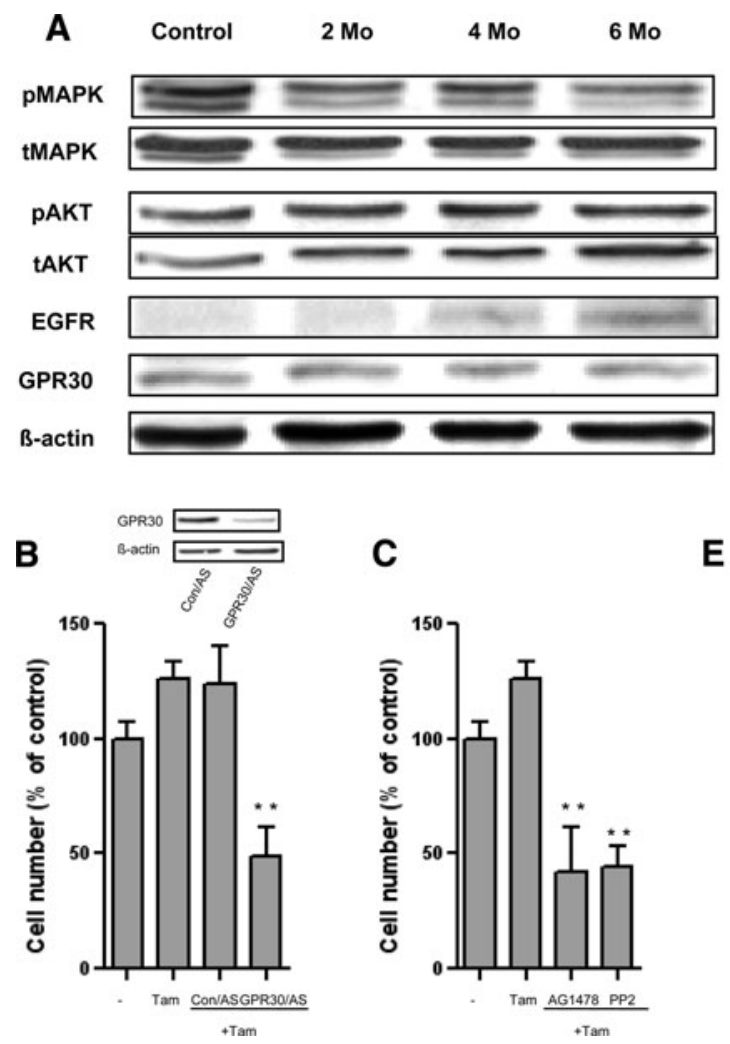

$\mathbf{E}$

Fig. 3 GPR30/growth factor receptor signaling in TAM-R cells. a Basal expression profile of TAM-R cells. Cell lysates were prepared from control cells ( 0 months) or TAM-R cells cultivated in presence of 10-nM Tam for 2, 4, or 6 months (Mo). The protein expression of GPR30, EGFR, and the basal phosphorylation of MAPK and Akt was examined by Western blot using specific antibodies. b, c, d Effect of GPR30 anti-sense oligonucleotide, EGFR inhibitor AG1478 and c-Src inhibitor PP2 on Tam agonist activity in TAM-R cells. TAM-R cells were $\mathbf{b}$ transiently transfected with control scrambled oligonucleotide (Con/AS) or with GPR30 anti-sense oligonucleotide (GPR30/AS) or c preincubated for $1 \mathrm{~h}$ with $1-\mu \mathrm{M}$ AG1478 or $5-\mu \mathrm{M}$ PP2. After that, they were treated with $1-\mu \mathrm{M}$ Tam for 5 days and the cell count measured $(\mathbf{b}, \mathbf{c})$ or the MAPK phosphorylation assayed by Western
To further investigate the role of growth factor signaling in Tam resistance, TAM-R cells were transfecte by GPR30 anti-sense oligonucleotides or were pretreated with small molecule inhibitor AG1478, which block EGFR activity. The knocking down of GPR30 by transfection of the cells with GPR30 anti-sense oligonucleotide abrogated the agonistic effect of Tam and led to significant growth inhibition of TAM-R cells (Fig. 3b). Similarly, simultaneous treatment of TAM-R cells with Tam and AG1478, reestablished the inhibitory effect of Tam on cell growth (Fig. 3c). It has been suggested that GPR30 can activate EGFR by activation of non-receptor tyrosin kinase c-Src [9]. To investigate this hypothesis the cells were preincubated with c-Src inhibitor PP2. As expected, the proliferative effect of Tam was completely blocked (Fig. 3c). Western blotting further demonstrated the role of GPR30 and EGFR cross talk in Tam resistance. As demonstrated in
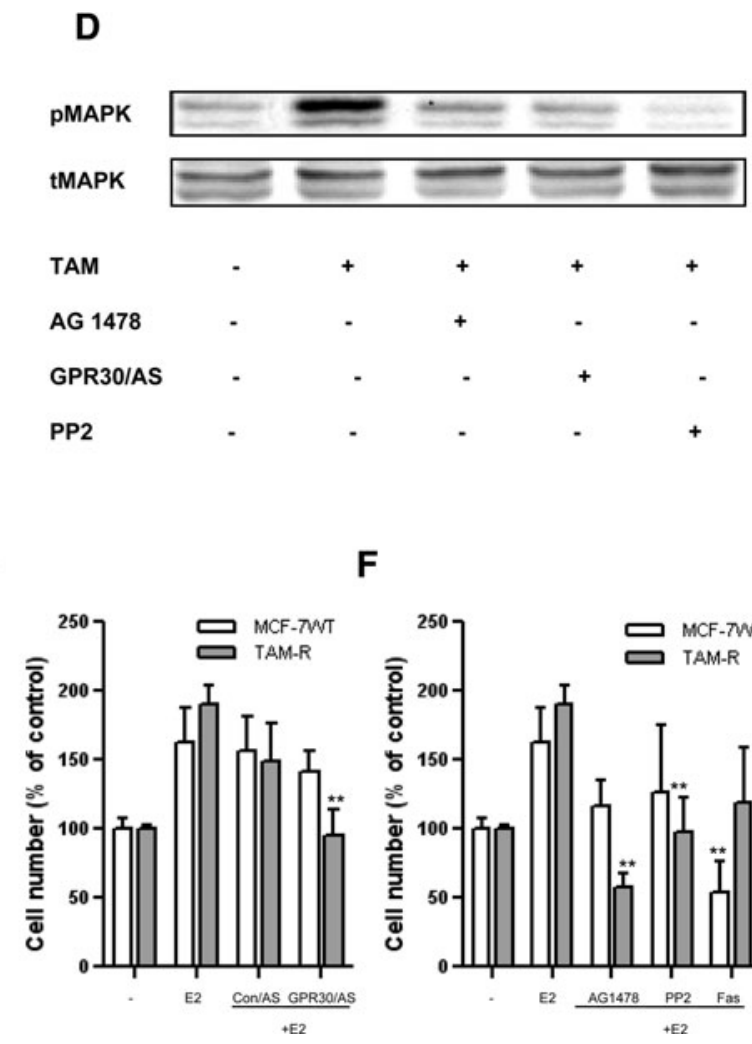

$\mathbf{F}$

blotting (d). Inset, cells transfected with control scrambled oligonucleotide (Con/AS) or with GPR30 anti-sense oligonucleotide (GPR30/ AS). B-actin was used as a loading control. Each experiment was repeated at least three times. The results are expressed as means \pm SD. $(* * P<0.01$, compare to the Tam treatment). e, f Growth effect of E2 on MCF-7WT and TAM-R cells. MCF-7WT and TAM-R cells were e transiently transfected with GPR30 anti-sense oligonucleotide or with control scrambled oligonucleotide (Con/AS) or $\mathbf{f}$ preincubated for $1 \mathrm{~h}$ with $1-\mu \mathrm{M}$ AG1478, 5- $\mu \mathrm{M}$ PP2, and $1-\mu \mathrm{M}$ fulvestrant (Fas) in the presence of 10-nM E2. After 5 days the cell count was measured. Each experiment was repeated at least three times. The results are expressed as means $\pm \mathrm{SD}(* * P<0.01$, compare to the E2 treatment) 
Fig. 3d, AG1478, PP2, and the knocking down of GPR30 reestablished the ability of Tam to inhibit MAPK phosphorylation in TAM-R cells. These results clearly suggested the role of GPR30/EGFR signaling pathway in mediation of Tam growth stimulation activity in TAM-R cells.

To determine whether GPR30/EGFR signaling plays a role in "non-genomic action" of E2, control cells and TAM-R cells were incubated with E2 in presence of AG1478 and c-Src kinase inhibitor PP2. The role of GPR30 was investigated by transfection of the cells with GPR30 anti-sense oligonucleotides. AG1478, PP2, and knocking down of GPR30 had not or demonstrated only a slight inhibition of E2-induced cell proliferation in MCF7WT (Fig. 3e, f). As expected, ER antagonist fulvestrant was able to abolish completely the cell proliferation of MCF-7WT cells, demonstrating that the "classic" genomic action of E2 is superior in wild-type cells. In contrast, cell proliferation effect of E2 in TAM-R cells was significantly diminished by GPR30 knocking down, AG1478, and PP2 (Fig. 3e, f), demonstrating the important role of GPR30/ EGFR cross talk for E2 signaling in TAM-R cells.

Long-term G1 treatment abrogates the responsiveness of MCF-7 cells to Tam

As demonstrated in Fig. 1a, the exposure of MCF-7WT cells to Tam leads to a reduction in cell number. To investigate further the possible role of GPR30 in mechanisms of Tam resistance, MCF-7WT cells were continuously exposed to 1-nM G1 over a period of 6 months. The cells cultured in G1-containing medium were named G1-R cells. Surprisingly, long-term exposure to G1 mimics the long-term exposure to Tam and abrogated its inhibitory effect. In G1-R cells Tam acted as agonist and induced the cell proliferation (Fig. 4a) and MAPK kinase phosphorylation
(Fig. 4b). Only high concentrations of Tam (15 and $20 \mu \mathrm{M})$ remained growth inhibitory. As expected, antisense oligonucleotide against GPR30 restored the growth inhibitory effect of Tam in G1-R (Fig. 4a) and abolished Tam-induced phosphorylation of MAPK (Fig. 4b).

\section{E2 up-regulates GPR30 expression}

During this subset of experiments, we observed an interesting fact, namely the incubation of TAM-R cells in medium containing FCS or E2, increased their sensitivity to G1. The simultaneous incubation of the cells with 10-nM E2 and 1-nM G1 led to a significant increase of cell proliferation over the proliferation caused by each substance alone. This indicates that both substances potentiate their growth stimulatory effect. The pretreatment of TAM-R cells with 10-nM E2 increased significantly the proliferation potential of GPR30 agonist G1 (Fig. 5a). In control cells this effect was not observed (data not shown). This data raised the question if E2 induces the GPR30 expression. To investigate this hypothesis, MCF-7 and TAM-R cells were incubated with 10-nM E2 for indicated times and GPR30 expression was assayed by Western blotting. E2 incubation increased GPR30 protein expression in both the cell types (Fig. 5b). However, TAM-R cells showed earlier increase in GPR30 level when compared to the control cells with peak stimulation at 2 and $6 \mathrm{~h}$, respectively. These results demonstrate that E2 up-regulates significantly GPR30 expression in TAM-R cells and increases additionally their sensitivity to G1.

To define more precisely the subcellular localization of GPR30 after E2 stimulation, we prepared fractions from plasma membrane and endoplasmic reticulum from MCF7WT and TAM-R cells. The protein expression level was detected by Western blot, where calnexin and $5^{\prime}$-nucleotidase were used as markers of endoplasmic reticulum and

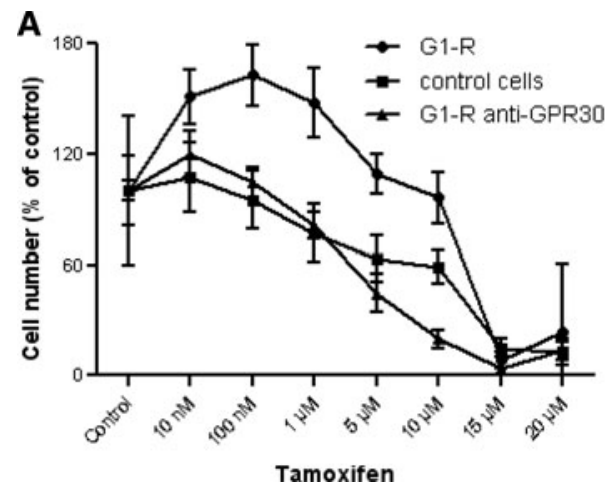

Fig. 4 Long-term G1 treatment of MCF-7WT cells altered their response to Tam. a MCF-7WT cells, parental cells cultured for 6 months with 1-nM G1 (G1-R cells) and G1-R cells transiently transfected with GPR30 anti-sense oligonucleotide were then treated with Tam in the indicated concentrations for 5 days and the cell
B

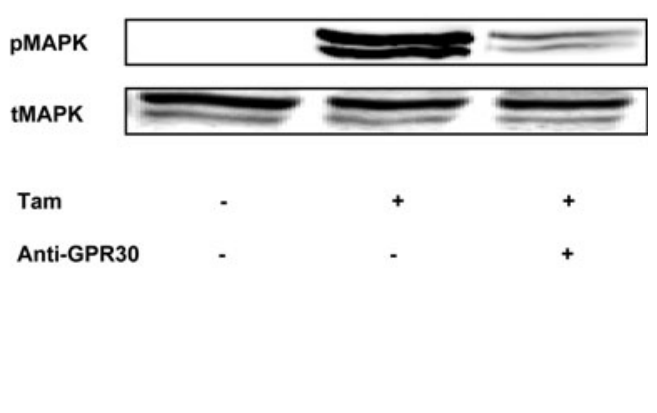

number was counted. Each experiment was repeated at least three times. The results are expressed as means \pm SD. b G1-R cells transfected or not with GPR30 anti-sense oligonucleotide, were incubated for $5 \mathrm{~min}$ with $1-\mu \mathrm{M}$ Tam. Then the phosphorylation level of MAPK was measured by Western blot using specific antibodies 


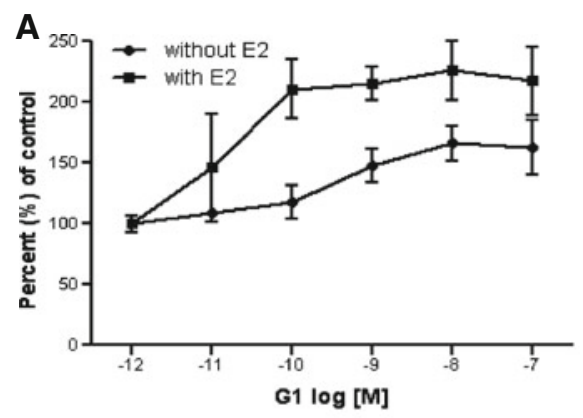

B
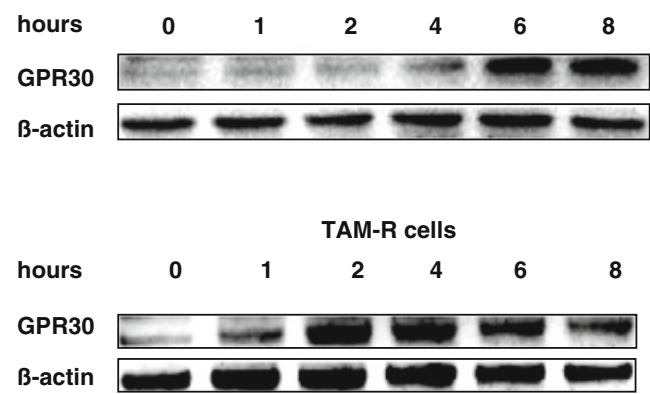

C

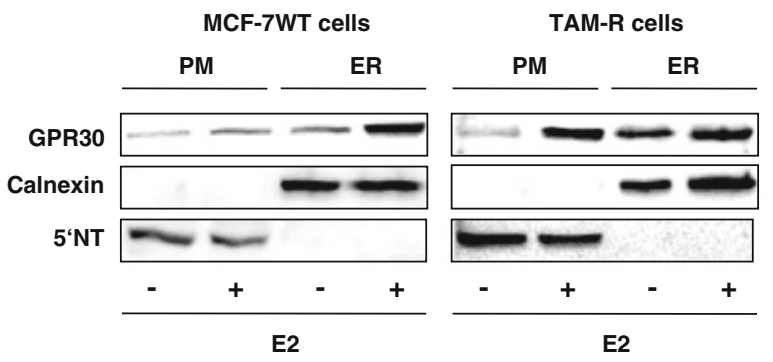

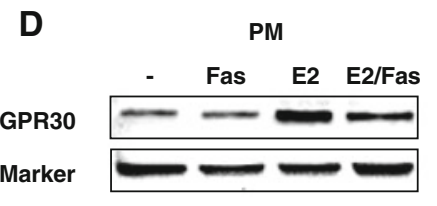

5‘NT

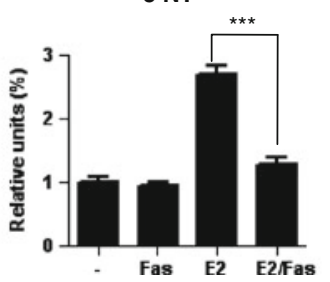

ER

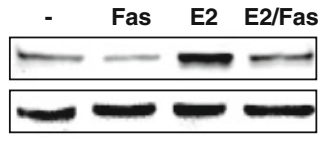

Calnexin

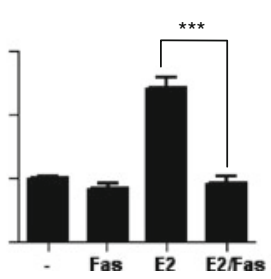

Fig. 5 E2-induced up-regulation of GPR30. a TAM-R cells were pretreated for $24 \mathrm{~h}$ with medium containing 1-nM E2 or not. After that the cells were treated with G1 in the indicated concentrations for 5 days and the cell number was counted. Each experiment was repeated at least three times. The results are expressed as means \pm SD. b MCF-7WT and TAM-R cells were incubated with 10-nM E2 for indicated time. GPR30 protein expression was measured by Western blot using specific antibody against GPR30. Membranes were re-blotted with an anti- $\beta$-actin antibody. c MCF7WT and TAM-R cells were treated with 10-nM E2 for 6 and $2 \mathrm{~h}$, respectively. The protein expression of GPR30 in plasma membrane

plasma membrane, respectively. MCF-7WT and TAM-R cells were stimulated with 10-nM E2. As demonstrated above, E2 stimulation up-regulates significantly GPR30 expression. Interestingly, after E2 stimulation the level of GPR30 in MCF-7WT cells was increased only in endoplasmic reticulum fraction (Fig. 5c, left panel). In TAM-R cells, a drastic increase of GPR30 was recovered in endoplasmic reticulum as well as in plasma membrane (Fig. 5c, right panel). These data indicate that in TAM-R cells E2 stimulates not only the GPR30 expression, but also its redistribution to the plasma membrane.

To investigate the role of ER in this process, TAM-R cells were incubated with E2 in the presence or absence of the ER antagonist fulvestrant. Because fulvestrant is an agonist for GPR30, we investigated its influence on GPR30 expression. Fulvestrant alone did not change the expression of GPR30 in TAM-R cells (Fig. 5d). However, fulvestrant abolished completely the E2-stimulated GPR30 expression in membrane and endoplasmic reticulum fractions (Fig. 5d). This observation suggests that E2-stimulated up-
(PM) and endoplasmic reticulum (ER) was investigated and compared to the expression level in untreated cells. $5^{\prime}$-nucleotidase $\left(5^{\prime}\right.$-NT) and calnexin were used as specific markers for plasma membrane and endoplasmic reticulum, respectively. d TAM-R cells were incubated with medium (-), 10-nM E2 for $2 \mathrm{~h}$ with or without pretreatment with 100-nM fulvestrant (Fas). $5^{\prime}$-nucleotidase $\left(5^{\prime}\right.$-NT) and calnexin were used as specific markers for plasma membrane and endoplasmic reticulum, respectively. Under the Western blot panels, a quantitative representation of the expression analysis is shown. The results are expressed as means $\pm \mathrm{SD}(* * * P<0.001)$

regulation and translocation of GPR30 to the cell membrane is ER-dependent.

\section{Discussion}

In this study, we investigated the role of GPR30 in the development of acquired Tam resistance. GPR30, a member of the big group of seven-spanning GPCR-receptor family, has been supposed to act as a transmembrane estrogen receptor $[14,15]$. Moreover, it has been suggested that Tam and fulvestrant, two ER antagonists, act as GPR30 agonists and stimulate cell proliferation in different cell types [16-19]. These results raise the question if GPR30 is involved in the increased estrogen agonist activity of Tam in Tam-resistant cells.

The role of GPR30 as a functional estrogen receptor remains a controversial topic $[8,20]$. Many works described GPR30 as an estrogen G-protein coupled receptor, whereas others suggest that GPR30 acts as a collaborator 
with ER in transmission of estrogen signaling [20]. In our experiments, E2 effect in wild-type MCF-7 cells was unchanged by the knocking down of GPR30, but completely inhibited by fulvestrant. In this regard, we can conclude that GPR30 plays a secondary role in transmitting any estrogen action in the parental cells. In these cells, ER remains the predominant signaling target for estrogen. In contrast, long-term exposure of MCF-7 cells to Tam increased their sensitivity to E2 and capability of GPR30 to mediate estrogen action. We supposed as a possible explanation an increase in receptor expression or functionality. Surprisingly, there was no increased basal expression of GPR30 in TAM-R cells when compared to MCF-7 cells.

Originally, GPR30 have been found to be localized to the endoplasmic reticulum, where it transduced the estrogen action resulting in increased $\mathrm{Ca}^{2+}$ mobilization and synthesis of phosphatidylinositol 3,4,5- trisphosphate [14]. Therefore, the second possible explanation was an increased synergism between ER and GPR30 with mobilization of the intracellular pool of GPR30. We found that E2 incubation increased GPR30 protein expression and it was more drastically in TAM-R cells (Fig. 5b). Very recently similar results have been found in endometrial cancer cells, where the basal mRNA level of GPR30 was significantly higher in presence of E2 [21]. Moreover, in TAM-R cells we observed an increase of cell surface expression of GPR30, which was completely abolished by $\mathrm{ER} \alpha$ inhibitor fulvestrant, but not by genistein, an ERß inhibitor (data not shown). It demonstrated that the presence of estrogen is necessary for GPR30 up-regulation/ translocation and might be an important milestone in development of acquired resistance. The importance of estrogen milieu for this process has been very recently confirmed [22]. GPR30 up-regulation can explain the increased sensibility of TAM-R cells to GPR30-specific agonist G1. The overexpression of GPR30 alone could not explain the entire mechanism of Tam resistance, but it may promote the rapid development of resistance in presence of its natural ligand in serum.

The cross talk between estrogen and growth factor signaling pathways as an important mechanism for endocrine therapy resistance in breast cancer is well established (for review see [23]). Activated GPR30 may transactivate EGFR by stimulating HB-EGF release [9]. GPR30 upregulation in TAM-R cells increases the possibility of cross talk with EGFR with a consequent MAPK and Akt activation [24]. This hypothesis is supported by the fact that in breast cancer specimens, GPR30-expression correlates significantly with overexpression of Her-2, another member of the EGFR-receptor family [25]. Recent results have shown a cross talk of GPR30 with activated EGFR and ER in hormone-positive cancer cells [26]. Moreover, the authors suggested that the EGFR can up-regulate GPR30, which in turn could contribute to failure of tamoxifen therapy [26].

Interestingly, only EGFR expression was slightly increased in MCF-7 cells after 6 months of treatment with Tam, which is inconsistent and controversially described in the literature [22, 27-29]. On the other hand, the basal phosphorylation of MAPK and Akt did not change during long-term treatment with Tam. However, Tam was able to increase significantly the MAPK phosphorylation in TAM$\mathrm{R}$ cells with consequent stimulation of cell growth. Tamstimulated expression of MAPK has been reported to be associated with Tam resistance in breast cancer patients [30]. Anyway, the Tam-induced cell growth and phosphorylation of MAPK in TAM-R cells was blocked by GPR30 anti-sense oligonucleotides or EGFR inhibitor AG1478. Additionally, Tam agonist activity was blocked by preincubation with $\mathrm{PP} 2$, an inhibitor of non-receptor tyrosin kinase c-Src which is known to mediate the E2stimulated EGFR activity [9, 31], as well as the cross talk between GPR30 and EGFR [16]. All these data suggest involvement of GPR30 and EGFR signaling in Tam agonistic activity in TAM-R cells.

A similar mechanism of Tam resistance has been proposed for membrane-bound ER [27]. However, the fact that ER protein does not contain hydrophobic transmembrane domains and membrane localizing sequence [23] make this suggestion disputable. In addition, the potential role of cross- talk between membrane-bound ER and EGFR in the mechanisms of Tam resistance in breast cancer remains unrealistic, because there is a negative correlation between ER and EGFR/Her-2 expression in human breast cancer and ER seems to be a repressor for EGFR [32, 33]. In contrast, recent results have demonstrated that GPR30 expression correlates significantly with Her-2 expression in breast cancer [25].

A nonsteroidal, highly selective agonist of GPR30 has been recently described. The chronic activation of GPR30 by G1 completely abolished the inhibitory effect of Tam. After long-term exposure of MCF-7 cells to G1, Tam does not act anymore as growth inhibitory, but as stimulatory with increased MAPK phosphorylation. Knocking down of GPR30 and inhibition of EGFR signaling, restored Tam inhibitory effect in these cells, confirming the importance of GPR30/EGFR cross talk for the development of Tam resistance in vitro. The activation of GPR30 in breast cancer by its natural ligand(s) in vivo might be an alternative mechanism supporting the development of Tam resistance.

Our results demonstrate for the first time the role of GPR30 in a Tam-resistance model (Fig. 6). Long-term treatment with Tam increases the sensitivity of the cells to E2 and leads to increase of E2-stimulated up-regulation of 


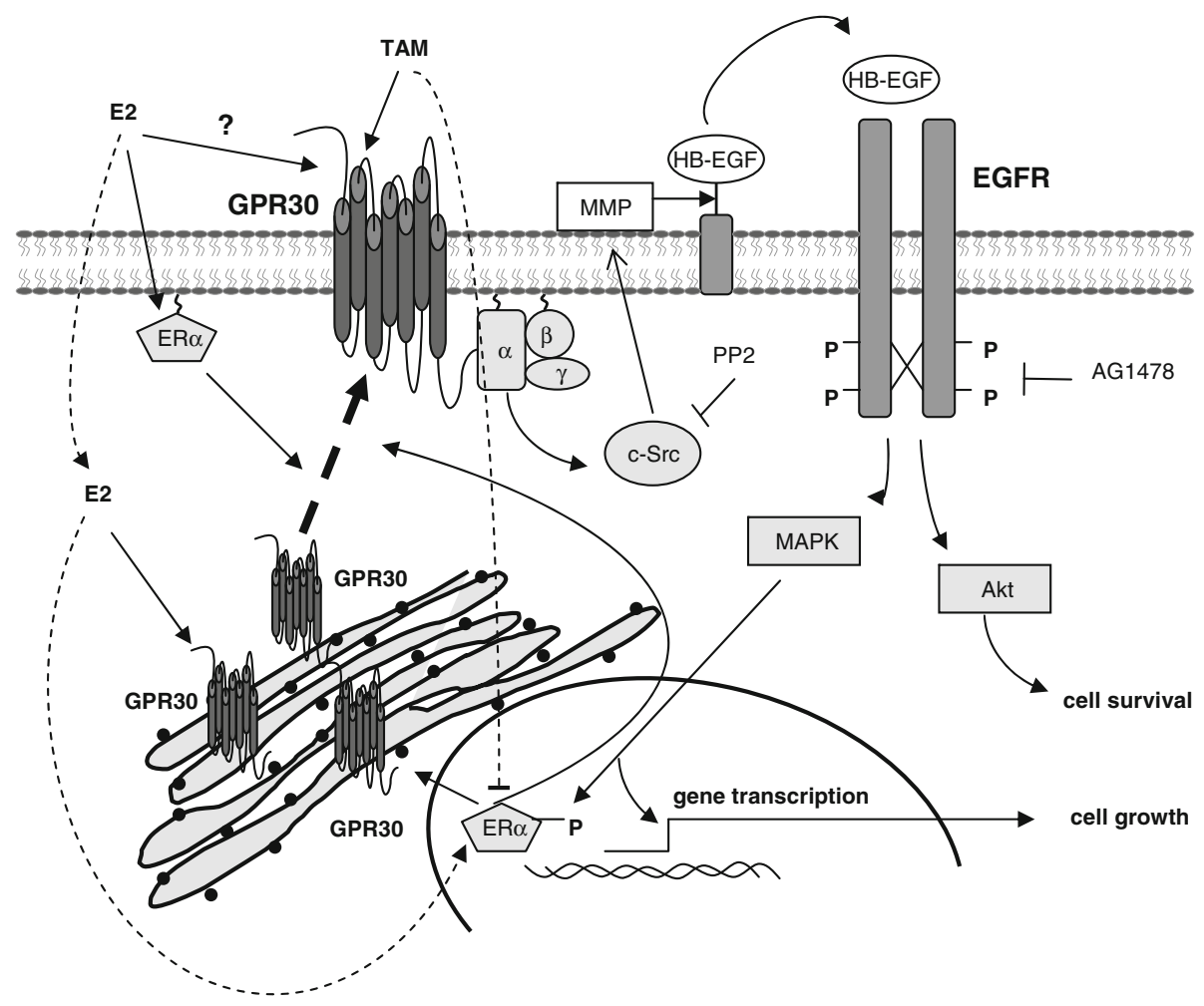

Fig. 6 Role of GPR30/EGFR signaling pathway in Tam resistance. Long-term treatment with Tam increased the sensitivity of the cells to E2 and led to an increase of E2-stimulated up-regulation of GPR30, with increased translocation of GPR30 from the endoplasmatic reticulum to the cell surface. Because Tam acts as an agonist for GPR30 [9], the overexpression of GPR30 converts Tam to a growth stimulator and increases its agonistic activity in TAM-R cells. Via activation of c-Src and matrix metalloproteinases (MMPs) GPR30 transactivates subsequently EGFR followed by phosphorylation of MAPK and Akt or even ER. Thus, MAPK and Akt can further

GPR30 and its recruitment and translocation from endoplasmatic reticulum to the cell surface. The overexpression of GPR30, converts Tam to a growth stimulator because its ability to act as an agonist for GPR30. GPR30 activates various G-proteins with subsequent activation of EGFR, which possibly occurs by activation of c-Src and matrix metalloproteinases (MMPs). The GPR30/EGFR cross talk is followed by phosphorylation of MAPK and Akt. Thus, MAPK and Akt can further stimulate transcription of different genes (even ER) with consequence, cell growth proliferation. Then, again, the phosphorylated ER can further up-regulate GPR30, establishing a vicious circle. Blockage of GPR30/EGFR signaling is a potential target to overlap the Tam resistance in breast cancer cells. A further investigation of the role of GPR30 in this process is needed.

Acknowledgments We thank Martina Stoklasek and Kerstin Werner for the excellent technical assistance. This work was supported by Deutsche Krebshilfe (Förderkennzeichen 108931). stimulate transcription of different genes independently of ER stimulation with consequence cell growth and cell proliferation. Then, again, the phosphorylated ER can further enhance the cell surface expression of GPR30, establishing a vicious circle. The Tam agonist activity can be inhibited by blocking the EGFR signaling by specific inhibitors (AG1478) or by interrupting the direct cross talk between GPR30 and EGFR by c-Scr inhibitor (PP2). Knocking down GPR30 with anti-sense oligonucleotide (ASO) is an alternative variant to restore inhibitory effect of Tam on cell growth

\section{References}

1. Tamoxifen for early breast cancer: an overview of the randomised trials (1998) Early breast cancer trialists' collaborative group. Lancet 351:1451-1467

2. Powles TJ, Ashley S, Tidy A, Smith IE, Dowsett M (2007) Twenty-year follow-up of the Royal Marsden randomized, double-blinded tamoxifen breast cancer prevention trial. J Natl Cancer Inst 99:283-290

3. Kurebayashi J (2005) Resistance to endocrine therapy in breast cancer. Cancer Chemother Pharmacol 56(Suppl 1):39-46

4. Nicholson RI, McClelland RA, Finlay P, Eaton CL, Gullick WJ, Dixon AR, Robertson JF, Ellis IO, Blamey RW (1993) Relationship between EGF-R, c-erbB-2 protein expression and Ki67 immunostaining in breast cancer and hormone sensitivity. Eur J Cancer 29A:1018-1023

5. Wright C, Nicholson S, Angus B, Sainsbury JR, Farndon J, Cairns J, Harris AL, Horne CH (1992) Relationship between cerbB-2 protein product expression and response to endocrine therapy in advanced breast cancer. Br J Cancer 65:118-121

6. Hutcheson IR, Knowlden JM, Madden TA, Barrow D, Gee JM, Wakeling AE, Nicholson RI (2003) Oestrogen receptor-mediated modulation of the EGFR/MAPK pathway in tamoxifen-resistant MCF-7 cells. Breast Cancer Res Treat 81:81-93 
7. Rae JM, Johnson MD (2005) What does an orphan G-proteincoupled receptor have to do with estrogen? Breast Cancer Res 7:243-244

8. Prossnitz ER, Oprea TI, Sklar LA, Arterburn JB (2008) The ins and outs of GPR30: a transmembrane estrogen receptor. J Steroid Biochem Mol Biol 109:350-353

9. Filardo EJ (2002) Epidermal growth factor receptor (EGFR) transactivation by estrogen via the G-protein-coupled receptor, GPR30: a novel signaling pathway with potential significance for breast cancer. J Steroid Biochem Mol Biol 80:231-238

10. Ignatov A, Lintzel J, Kreienkamp HJ, Schaller HC (2003) Sphingosine-1-phosphate is a high-affinity ligand for the G protein-coupled receptor GPR6 from mouse and induces intracellular $\mathrm{Ca}^{2+}$ release by activating the sphingosine-kinase pathway. Biochem Biophys Res Commun 311:329-336

11. Ignatov A, Robert J, Gregory-Evans C, Schaller HC (2006) RANTES stimulates $\mathrm{Ca}^{2+}$ mobilization and inositol trisphosphate (IP3) formation in cells transfected with $\mathrm{G}$ protein-coupled receptor 75. Br J Pharmacol 149:490-497

12. Jordan NJ, Gee JM, Barrow D, Wakeling AE, Nicholson RI (2004) Increased constitutive activity of PKB/Akt in tamoxifen resistant breast cancer MCF-7 cells. Breast Cancer Res Treat 87:167-180

13. Osborne CK, Shou J, Massarweh S, Schiff R (2005) Crosstalk between estrogen receptor and growth factor receptor pathways as a cause for endocrine therapy resistance in breast cancer. Clin Cancer Res 11:865s-870s

14. Revankar CM, Cimino DF, Sklar LA, Arterburn JB, Prossnitz ER (2005) A transmembrane intracellular estrogen receptor mediates rapid cell signaling. Science 307:1625-1630

15. Thomas P, Pang Y, Filardo EJ, Dong J (2005) Identity of an estrogen membrane receptor coupled to a $\mathrm{G}$ protein in human breast cancer cells. Endocrinology 146:624-632

16. Filardo EJ, Quinn JA, Bland KI, Frackelton AR Jr (2000) Estrogen-induced activation of Erk-1 and Erk-2 requires the G protein-coupled receptor homolog, GPR30, and occurs via transactivation of the epidermal growth factor receptor through release of HB-EGF. Mol Endocrinol 14:1649-1660

17. Maggiolini M, Vivacqua A, Fasanella G, Recchia AG, Sisci D, Pezzi V, Montanaro D, Musti AM, Picard D, Ando S (2004) The $\mathrm{G}$ protein-coupled receptor GPR30 mediates c-fos up-regulation by 17 beta-estradiol and phytoestrogens in breast cancer cells. $\mathrm{J}$ Biol Chem 279:27008-27016

18. Vivacqua A, Bonofiglio D, Recchia AG, Musti AM, Picard D, Ando S, Maggiolini M (2006) The G protein-coupled receptor GPR30 mediates the proliferative effects induced by 17 betaestradiol and hydroxytamoxifen in endometrial cancer cells. Mol Endocrinol 20:631-646

19. Vivacqua A, Bonofiglio D, Albanito L, Madeo A, Rago V, Carpino A, Musti AM, Picard D, Ando S, Maggiolini M (2006) 17 beta-estradiol, genistein, and 4-hydroxytamoxifen induce the proliferation of thyroid cancer cells through the $\mathrm{g}$ protein-coupled receptor GPR30. Mol Pharmacol 70:1414-1423

20. Levin ER (2009) G protein-coupled receptor 30: estrogen receptor or collaborator? Endocrinology 150:1563-1565
21. Leblanc K, Sexton E, Parent S, Belanger G, Dery MC, Boucher V, Asselin E (2007) Effects of 4-hydroxytamoxifen, raloxifene and ICI 182780 on survival of uterine cancer cell lines in the presence and absence of exogenous estrogens. Int $\mathrm{J}$ Oncol 30:477-487

22. Fan P, Yue W, Wang JP, Aiyar S, Li Y, Kim TH, Santen RJ (2009) Mechanisms of resistance to structurally diverse antiestrogens differ under premenopausal and postmenopausal conditions: evidence from in vitro breast cancer cell models. Endocrinology 150:2036-2045

23. Bedard PL, Freedman OC, Howell A, Clemons M (2008) Overcoming endocrine resistance in breast cancer: are signal transduction inhibitors the answer? Breast Cancer Res Treat 108:307-317

24. Levin ER (2003) Bidirectional signaling between the estrogen receptor and the epidermal growth factor receptor. Mol Endocrinol 17:309-317

25. Filardo EJ, Graeber CT, Quinn JA, Resnick MB, Giri D, DeLellis RA, Steinhoff MM, Sabo E (2006) Distribution of GPR30, a seven membrane-spanning estrogen receptor, in primary breast cancer and its association with clinicopathologic determinants of tumor progression. Clin Cancer Res 12:6359-6366

26. Vivacqua A, Lappano R, De Marco P, Sisci D, Aquila S, De Amicis F, Fuqua SA, Ando S, Maggiolini M (2009) G Proteincoupled receptor 30 expression is up-regulated by EGF and TGF $\alpha$ in estrogen receptor $\alpha$-positive cancer cells. Mol Endocrinol. doi: 10.1210/me.2009-0120

27. Fan P, Wang J, Santen RJ, Yue W (2007) Long-term treatment with tamoxifen facilitates translocation of estrogen receptor alpha out of the nucleus and enhances its interaction with EGFR in MCF-7 breast cancer cells. Cancer Res 67:1352-1360

28. Gee JM, Harper ME, Hutcheson IR, Madden TA, Barrow D, Knowlden JM, McClelland RA, Jordan N, Wakeling AE, Nicholson RI (2003) The antiepidermal growth factor receptor agent gefitinib (ZD1839/Iressa) improves antihormone response and prevents development of resistance in breast cancer in vitro. Endocrinology 144:5105-5117

29. Shou J, Massarweh S, Osborne CK, Wakeling AE, Ali S, Weiss H, Schiff R (2004) Mechanisms of tamoxifen resistance: increased estrogen receptor-HER2/neu cross-talk in ER/HER2positive breast cancer. J Natl Cancer Inst 96:926-935

30. Gutierrez MC, Detre S, Johnston S, Mohsin SK, Shou J, Allred DC, Schiff R, Osborne CK, Dowsett M (2005) Molecular changes in tamoxifen-resistant breast cancer: relationship between estrogen receptor, HER-2, and p38 mitogen-activated protein kinase. J Clin Oncol 23:2469-2476

31. Razandi M, Pedram A, Park ST, Levin ER (2003) Proximal events in signaling by plasma membrane estrogen receptors. J Biol Chem 278:2701-2712

32. deFazio A, Chiew YE, Sini RL, Janes PW, Sutherland RL (2000) Expression of c-erbB receptors, heregulin and oestrogen receptor in human breast cell lines. Int J Cancer 87:487-498

33. Wilson MA, Chrysogelos SA (2002) Identification and characterization of a negative regulatory element within the epidermal growth factor receptor gene first intron in hormone-dependent breast cancer cells. J Cell Biochem 85:601-614 